\title{
Non-Erosive Reflux Disease Manifested Exclusively by Protracted Hiccups
}

\author{
Andrés de Hoyos, $\mathrm{MD}^{1 *}$, Edgar A Esparza, $\mathrm{MD}^{2}$ and María Cervantes-Sodi, $\mathrm{MD}^{3}$ \\ Departments of ${ }^{1}$ Gastroenterology and ${ }^{2}$ Internal Medicine, Angeles del Pedregal Hospital, México City, México, ${ }^{3}$ Universidad Panamericana, \\ Escuela de Medicina, México City, México
}

Hiccups are a benign physiological feature affecting almost everyone at one time or another. They tend to be short-lived and do not affect quality of life; however, there are various pathologies that may present with long-lasting hiccups. These are grouped into 3 categories according to their duration: acute, persistent and intractable or protracted hiccups. Intractable hiccups last longer than 2 months and are usually associated with more severe conditions. The association between intractable hiccups and reflux disease has not been previously documented by objective methods. This report describes the case of a 23-year-old female who presented with protracted hiccups; all other organic pathologies were ruled out, and endoscopy and conventional pH-metry confirmed a diagnosis of non-erosive reflux disease as the unique cause.

(J Neurogastroenterol Motil 2010;16:424-427)

Key Words

Electric impedance; Gastroesophageal reflux; Hiccup; Proton pump inhibitors; Rabeprazole

\section{Introduction}

Hiccups are a benign physiological feature that most people experience at some point in their lives. They tend to be shortlived and do not significantly affect quality of life. Although hiccups are an involuntary and self-limited symptom, they can become an exhausting manifestation of disease. There are various pathologies that may present with long-lasting hiccups. ${ }^{1}$

Hiccups are produced by a spontaneous, sudden and fast contraction of the diaphragm and accessory muscles of inspiration, followed by the sudden inhibition of these muscles, which produces an abrupt closure of the glottis and interrupts the air column to produce the typical sound. The neurological mechanisms of hiccups are integrated by an afferent and efferent pathway mediated by the phrenic nerve, the sympathetic chain and the vagus nerve. The pathway involves a central neurological relief in the hypothalamus and an efferent pathway that reaches the diaphragm, glottis and intercostal muscles via the phrenic nerve. ${ }^{2,3}$

Hiccups are grouped into 3 categories according to their duration. Acute hiccups, which last less than 48 hours, are mainly associated with several gastric alterations, such as gastric distension, gastritis, tobacco use or alcohol ingestion. Persistent hiccups, in contrast, have a duration between 48 hours and less than 2 months. Finally, intractable or protracted hiccups, which last longer than 2 months, are called "singultus." Singultus may re-

Received: August 15, 2010 Revised: September 24, 2010 Accepted: September 30, 2010

(c) This is an Open Access article distributed under the terms of the Creative Commons Attribution Non-Commercial License (http://creativecommons. org/licenses/by-nc/3.0) which permits unrestricted non-commercial use, distribution, and reproduction in any medium, provided the original work is properly cited.

*Correspondence: Andrés de Hoyos, MD Angeles Del Pedregal Hospital, Camino a Santa Teresa No 1055, Consultorio 119, Col: Héroes de Padierna, México City 10700 , México

Tel: +52-55-55688946, Fax: +52-55-55688946, E-mail: andehoyos@yahoo.com

Financial support: None.

Conflicts of interest: None. 
sult from intestinal or CNS cancer, metabolic disorders, drugs, anesthesia, myocardial infarction, demyelination or other conditions. $^{3-6}$

In general, most of the causes of hiccups originate in the digestive tract, and the CNS is also often involved. The association between hiccups and reflux disease has not been previously documented by objective methods. The aim of the present report was to describe a case where the presence of gastroesophageal reflux disease was diagnosed based on the presentation of hiccups and supported by conventional and impedance pH-metry.

\section{Case Report}

This case involves a 23-year-old female with no history of alcoholism, smoking or allergies, who was referred for ureteropyelic stenosis, which was diagnosed at 16 years old, and Raynaud's disease, which was diagnosed at 17 years old.

Her symptoms first began in January, 2 years prior to presentation, with a sudden onset of hiccups, which evolved over 10 months. The first stage of the work-up involved several medical examinations, including a computed tomography scan of her head, neck, chest and abdomen as well as complete blood count, blood chemistry, urine test, anti-nuclear antibodies, anti-DNA antibodies, anti-Smith, anti-histone, anti-centromere, anti-Ro and anti-La tests, which were all negative.

A gastroenterology evaluation was initiated and included an esophago-gastro-duodenoscopy and pH-metry. The esophagogastro-duodenoscopy revealed a normal esophagus but showed petechial gastritis in the body and fundus of the stomach. A high exposition and an elevated number of reflux events were documented by conventional pH-metry: a total of $7.8 \%$ of the time at $\mathrm{pH}<4$ and 271 reflux events (Fig. 1). A total of 16 hiccup events occurred in 24 hours of the test, 12 of which coincided with reflux. The symptom-association probability (SAP) with respect to the hiccups was $97.4 \%$, and the symptom index (SI) was

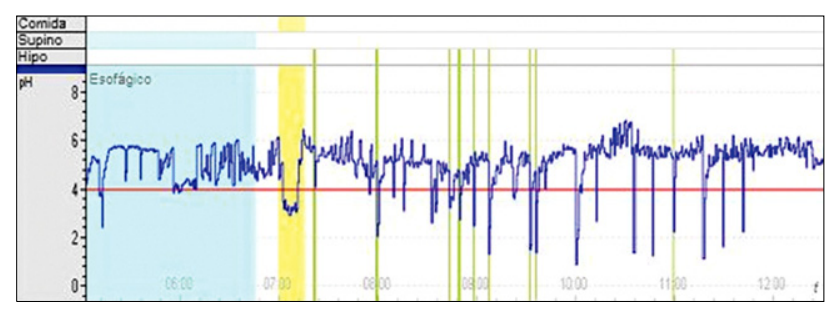

Figure 1. Correlation of hiccups (green vertical lines) with $\mathrm{pH}$ decreases (drops in the $\mathrm{pH}$ line).
$45.5 \%$. In view of these findings, the hypothesis that the hiccups were a manifestation of atypical gastroesophageal reflux was justified.

Treatment was started with various proton pump inhibitors (PPIs), H2-inhibitors, prokinetics and a decrease of approximately $50 \%$ in the number of hiccup events was achieved.

After 2 months, chlorpromazine was added to finalize control of the hiccups, and this resulted in a decrease of $82 \%$ in the number of hiccup events. However, this medication had to be withdrawn due to poorly tolerated side effects (Table 1), such as severe dizziness.

During the 18th month after presentation, omeprazole was changed to rabeprazole, which has a faster onset time. This lead to a very positive outcome because the hiccups occurred only 3 times per week (reported in Table 1 as 0.42 on average).

In view of the lack of a total response to the medications, an intraluminal impedance $\mathrm{pH}$-metry was performed during the

Table 1. Correlation of the Clinical Presentation and Treatment

\begin{tabular}{clc}
\hline Period (mo) & \multicolumn{1}{c}{ Anti-reflux treatment } & Hiccups/day \\
\hline $1-10^{\mathrm{a}}$ & None & 16 \\
$11-12$ & Esomeprazole/metoclopramide & 8 \\
$12-14$ & Plus domperidone/chlorpromazine & 3 \\
$14-15$ & Omeprazole/metoclopramide/domperidone & $4-5$ \\
$15-17$ & Omeprazole/domperidone & 8 \\
18 & Rabeprazole/domperidone & 0.42 \\
$19^{\mathrm{b}}$ & None & $8-9$ \\
$20-24$ & Omeprazole/domperidone & $4-5$ \\
\hline
\end{tabular}

${ }^{\mathrm{a}}$ Conventional $\mathrm{pH}$-metry test monitoring, ${ }^{\mathrm{b}}$ Intraluminal impedance $\mathrm{pH}$-metry monitoring

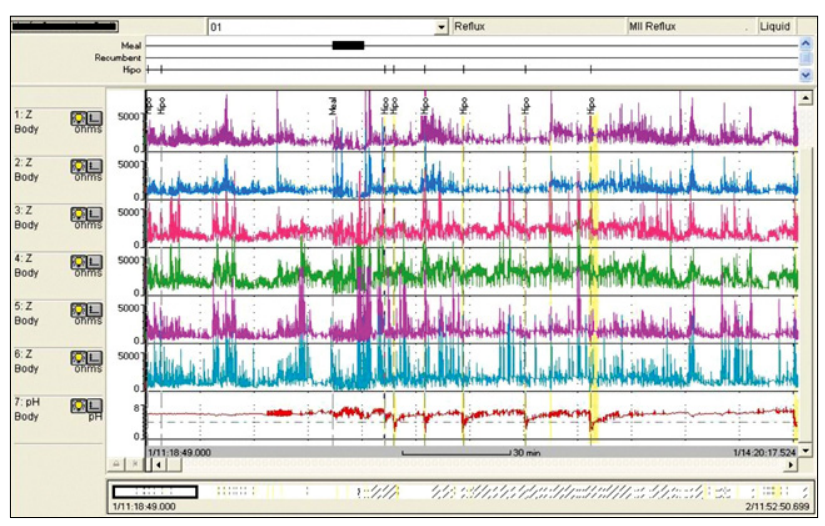

Figure 2. Representative portion of the esophageal impedance $\mathrm{pH}$ recording without the use of proton pump inhibitors showing an association between the hiccup episodes (yellow vertical lines) and the acid events (drops in the $\mathrm{pH}$ line). 
19th month without the use of PPIs; this was done to rule out non-acid reflux episodes and confirm the application of an appropriate treatment (Fig. 2). The results were as follows: 17 hiccups; 35 reflux episodes, 24 of which were reported as acid reflux and 11 as non-acid reflux and $2.1 \%$ of the time at $\mathrm{pH}<4$. In this test, the acid events were better correlated with the hiccups with a SAP of $100 \%$ and an SI of $82 \%$, which confirmed the diagnosis of acid reflux as the unique cause of the patient's symptoms.

In the 20th month, the patient decided to change her treatment from rabeprazole to omeprazole because of its lower cost.

After 2 years, the control of the hiccups had substantially improved with the use of PPIs, and the patient only experienced 4 to 5 hiccup events per day. To date, this strategy of maintenance dosage with PPIs has been effective; however, if there was a decline in her condition, we would consider adding additional pharmacological agents. If all pharmacological approaches fail, a final option would be fundoplication surgery.

As a complement to the screening, an esophageal manometry of the patient was performed using a Medtronic Poligraf without the use of PPIs and prokinetics. The patient displayed an effective esophageal motility with an amplitude pressure in the esophageal body $>30 \mathrm{mmHg}$. Nevertheless, in the distal esophagus, a hypotensive lower esophageal sphincter resting pressure of only $4.4 \mathrm{mmHg}$ was registered.

\section{Discussion}

The present case illustrates that sometimes, when facing persistent hiccups, we must rule out the presence of gastroesophageal reflux disease, which may produce a recurrent stimulation of the arch reflex that is likely due to irritation of the neural terminals connected to the gastro-esophageal mucosa. After other organic pathologies were ruled out by the work-up, the use of conventional $\mathrm{pH}$ monitoring was able to establish a diagnosis of reflux disease as the cause of the hiccups. ${ }^{7}$

Some features of our patient should be highlighted because she belongs to the non-erosive reflux disease (NERD) group with atypical symptoms. ${ }^{8}$ Similar to our case, there is only a partial response to pharmacological treatment in this population of patients, and it is accepted that a considerable percentage of this group (20\%-30\%) have a poor response to PPIs compared to those with erosive esophagitis. ${ }^{9}$ On the other hand, these NERD patients, who have increased distal esophageal acid exposure, present a higher proportion of symptom resolution with PPI therapy; these characteristics correlate with the elevated acid ex- posure and the good response to PPIs shown in this case. ${ }^{10}$

An important parameter that indicates a good association between hiccups and reflux is the presence of a positive SAP. ${ }^{11}$ This expresses the probability that the patient's symptoms may be related to reflux and is calculated using the Fisher's Test, which quantifies the probability that the observed distribution is not produced by chance; this guarantees that the result was not obtained at random and therefore, achieves greater certainty. ${ }^{12} \mathrm{On}$ the contrary, the SI was negative but was very close to a positive result. This probably occurred because the SI does not take the total number of reflux episodes into account, and a symptom index might be associated with reflux by chance. Therefore, the numerical result may be due to coincidence. ${ }^{13}$

When a case of hiccups becomes persistent or intractable, it is likely to result from serious pathophysiological processes that affect a component of the hiccup reflex mechanism. According to Martínez and Villamil, ${ }^{3}$ in the hospitalized patients, the 2 most common etiologies of intractable hiccups are digestive tract disorders (62.5\%) and CNS diseases (33.3\%). Medication use is another frequent cause in patients with organic pathologies. Most persistent hiccups are associated with organic conditions and occur more frequently in men $(\geq 82 \%) .{ }^{14}$ However, our patient was female, and we did not discover any common organic pathologic causes. Although the literature contains reports of rare causes of hiccups, the presence of NERD should always be considered if the work-up does not reveal a clear etiology because NERD treatment can offer a better outcome and prognosis.

Many drugs have been used to treat hiccups. Some of these have more specific uses and are intended to treat more specific causes. The most common initial drug for the treatment of chronic hiccups is metoclopramide, which is useful because it blocks the dopamine receptors in the chemoreceptor trigger zone of the CNS. ${ }^{15}$ Chlorpromazine and haloperidol also have antidopaminergic mechanisms of action ${ }^{16}$ and are effective ${ }^{17}$ at stopping intractable hiccups.

Moreover, several anticonvulsant agents are used to treat intractable hiccups. Phenytoin, valproic acid and carbamazepine can all be effective when used at typical anticonvulsant doses. ${ }^{18}$ Gabapentin has been shown to be more effective when CNS lesions are present or in other specialized situations.

Recently, baclofen has emerged as a safe and often effective treatment for protracted hiccups, and it results in a complete resolution in up to $82 \%$ of cases. It is used to treat patients with an unknown cause of hiccups or those who have failed to respond to treatment of a documented esophageal disease. ${ }^{19}$ 
In conclusion, after an extensive work-up of hiccups, if the symptoms seem to be secondary to NERD, we strongly recommend starting treatment with PPIs at elevated doses. If it becomes necessary, addition of any of the other treatments described in this report may also be beneficial.

\section{References}

1. Morrison WK. Hiccup. Br Med J 1971;2:709.

2. Fass R, Higa L, Kodner A, Mayer EA. Stimulus and site specific induction of hiccups in the oesophagus of normal subjects. Gut 1997; 41:590-593.

3. Martínez Rey C, Villamil Cajoto I. Hiccup: review of 24 cases. Rev Med Chile 2007;135:1132-1138.

4. Howard RS. Persistent hiccups. BMJ 1992;305:1237-1238.

5. Viera AJ, Sullivan SA. Remedies for prolonged hiccups. Am Fam Physician 2001;63:1684-1686.

6. Krysiak W, Szabowski S, Stepien M, Krzywkowska K, Krzywkowski A, Marciniak P. Hiccups as a myocardial ischemia symptom. Pol Arch Med Wewn 2008;118:148-151.

7. Redondo-Cerezo E, Viñuelas-Chicano M, Pérez-Vigara G, et al. A patient with persistent hiccups and gastro-oesophageal reflux disease. Gut 2008;57:763.

8. Longo JD, Orlando RC. Nonerosive reflux disease. Minerva Gastroenterol Dietol 2007;53:127-141.

9. Dean BB, Gano AD Jr, Knight K, Ofman JJ, Fass R. Effectiveness of proton pump inhibitors in nonerosive reflox disease. Clin Gas- troenterol Hepatol 2004;2:656-664.

10. Lind T, Havelund T, Carlsson R, et al. Hertburn without oesophagitis: efficacy of omeprazole therapy and features determining therapeutic response. Scand J Gastroenterol 1997;32:974-979.

11. Bredenoord AJ, Weusten BL, Smout AJ. Symptom association analysis in ambulatory gastro-oesophageal reflux monitoring. Gut 2005; 54:1810-1817.

12. Weusten BL, Roelofs JM, Akkermans LM, Van Berge-Henegouwen GP, Smout AJ. The symptom-association probability: an improved method for symptom analysis of 24-hour esophageal $\mathrm{pH}$ data. Gastroenterology 1994;107:1741-1745.

13. Ward BW, Wu WC, Richter JE, Lui KW, Castell DO. Ambulatory 24-hour esophageal $\mathrm{pH}$ monitoring. Technology searching for a clinical application. J Clin Gastroenterol 1986;8(suppl 1):59-67.

14. Wilkes G. Hiccups. URL: http://emedicine.medscape.com/article/ 775746-overview (accessed 15/jun/2010)

15. Madanagopolan N. Metoclopramide in hiccup. Curr Med Res Opin 1975;3:371-374.

16. Friedman NL. Hiccups: a treatment review. Pharmacotherapy 1996; 16:986-995.

17. Ives TJ, Fleming MF, Weart CW, Bloch D. Treatment of intractable hiccups with intramuscular haloperidol. Am J Psychiatry 1985; 142:1368-1369.

18. Jacobson PL, Messenheimer JA, Farmer TW. Treatment of intractable hiccups with valproic acid. Neurology 1981;31:1458-1460.

19. Guelaud C, Similowski T, Bizec JL, Cabane J, Whitelaw WA, Derenne JP. Baclofen therapy for chronic hiccup. Eur Respir J 1995; 8:235-237. 